\title{
The effect of nano-concrete on the form of high-rise buildings in sustainable agriculture
}

\author{
Bahareh Golkar*, Sasan Keyvanloo Shahrestanaki \\ Department of Architecture, Toos Higher Education Institute, Mashhad, Iran \\ Email address: \\ bahar.golkar@yahoo.com (B. Golkar), sasan_keyvanloo@yahoo.com (S. K. Shahrestanaki)
}

To cite this article:

Bahareh Golkar, Sasan Keyvanloo Shahrestanaki. The Effect of Nano-Concrete on the Form of High-Rise Buildings in Sustainable Agriculture. International Journal of Science, Technology and Society. Special Issue: Research and Practice in Architecture and Urban Studies in Developing Countries. Vol. 3, No. 2-1, 2015, pp. 5-10. doi: 10.11648/j.ijsts.s.2015030201.12

\begin{abstract}
Construction of modern high-rise concrete buildings meets the need for more accommodation of people and their demands to live and work in cities. The use of new technologies such as nano particles in construction can be one of the effective factors determining the form of a high-rise building in terms of architectural features such as performance, strength and durability, and safety issues. This study aims to examine nano concrete features in construction of high-rise buildings with appropriate form by using peripheral technologies and considering the cultural, social, and regional contents which are the objectives of sustainable development. On the other hand, some appropriate recommendations are made in this regard.
\end{abstract}

Keywords: Nano Particles, High-Rise Buildings, Form, Sustainable Architecture

\section{Introduction}

Advances in technology as well as humans need to various structures, have led to conducting extensive research on properties and behavior of materials which has consequently resulted in innovations in various types of structures and also the use of different materials [1]. Nanotechnology is not a new field but it is a new approach in other fields. Nanotechnology provides a new perspective of production at the nano-scale with different properties and atomic arrangements. The objective of nanotechnology is in fact to make things atom by atom with a bottom-up approach, which has been done by nature for millions of years [2]. Considering the rapid growth of scientific and practical research on nano science and technology in all fields and industries, very little attention has been paid to the implications of this phenomenon in buildings and generally in construction industry, but recently with regard to the role of nano strengtheners and consolidators in construction materials, a new wave of nano application has covered the construction industry with an increasing speed [1]. The present research aims to investigate the features of nano in construction of high-rise buildings with suitable forms.

\section{Concrete, Nanotechnology, High-Rise Buildings}

Concrete is used as an important material in construction industry. Natural Pozzolan powder is added to the concrete in order to increase its durability, reduce its production cost and the environmental pollution, but it reduces the concrete resistance at early ages. In recent years, the use of nano particles for improving the properties of concrete has drawn the attention of many researchers in the field of concrete technology towards itself. In order to solve the problem of high specific weight of concrete, lightweight concrete is used but the problem here is the resistance which is solved by using nano particles to fill the pores of the concrete and to increase its resistance [1]. In order to build a high-rise concrete building focusing on the form is very important.

In other words, according to new technologies such as the use of nano particles which will make it possible to build lightweight structures with high resistance, it is quite clear that a suitable method for a high-rise building is required with regard to the use of nano materials and of course "sustainable development" [6]. Proper use of tall buildings can effectively help solve the problems and develop a suitable and favorable environment, but ignoring the issues of such buildings will be associated with negative 
consequences. On the other hand, after a century of experiencing modern architecture, very complicated problems will occur in the environment. The world situation at the beginning of the $21^{\text {st }}$ century testifies an unsustainable development. Following this matter, a new concept is proposed entitled "sustainable development" due to the important role of the built environment [5].

Khazaeni et al. (2011) examined the effect of silica nano particles on the mechanical properties improvement of concrete by increasing the grade of cement [3]. They concluded that silica nano particles prevented the development of micro cracks and thus the resistance of silica nano particle samples increased in spite of increasing the grade of cement. Ahmadi Moghadam et al. [1] studied the lightweight nano-concrete. They stated that by increasing the same amount of micro silica in the concrete samples, the ones with silica nano particles were more resistant. This could be due to the fact that silica nano particles act in a space smaller than micrometer and form the hardener material and thus lead to the increase of concrete structure, decrease of permeability, and ultimately increase of concrete resistance and strength. Khazaeni's and Ahamdi's studies investigated the mechanical properties of standard concrete samples that can be applied to a concrete building, as well. A tall concrete building is a concrete structure which is tried to be made as much lightweight and resistant as possible by the structure designers while observing the architectural principles and features of a high-rise building. Golabchi [6] in an article did research on some criteria to design and construct high-rise buildings and studied them in terms of architectural features. Gorji [6] criticized sustainable architecture from the environment perspective and outlined the principles of sustainable architecture in his research. Shahbazi et al. [6] investigated sustainable architecture in terms of the use of solar energy. In the reviewed studies and the other references mentioned at the end of the article, the effect of nano particles in high-rise concrete buildings has not been investigated in terms of the principles of sustainable architecture.

\section{Nano Concrete}

Recently, nanotechnology has remarkably attracted the researchers towards itself which is due to the new and useful potentials of nano particles. The size of nano particles can significantly improve the properties of the particles with the same chemical combination. An example is depicted in Figure (1). Due to their extremely small size, nano particles have unique chemical and mechanical properties that distinguish them from common materials. Due to their unique properties, nano particles have drawn many attentions towards themselves [2]. Concrete can be considered as a nano-material because it can be examined from physical perspective despite the mentioned pores and cavities in concrete and hydrated cement paste as well as chemical perspective with regard to hydration reactions and chemical reactions occurring in concrete during the attack by chemical aggressive agents and also harmful physical agents from nano technology perspective [1].

\section{Nano Particles}

Some natural pozzolans are in fact the shell stones and ashes remaining from non-crystalline volcanic activities. Taftan pozzolan powder is added to the concrete as a natural pozzolan to increase the durability and decrease the costs of concrete and also to reduce the environmental pollution resulting from cement production. This reduces the strength of concrete at early ages [1].

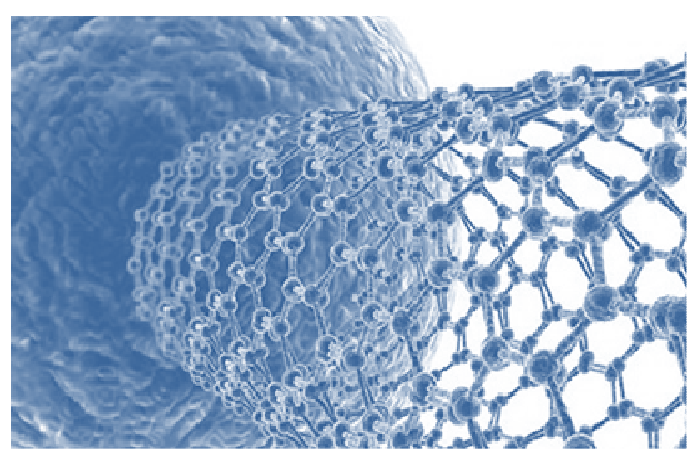

Figure 1. Nanotechnology and concrete [2]

By natural pozzolan it is means that no operation is needed to modify its chemical and mineralogical characteristics and it can be applied directly [3]. With regard to different volcanoes in our country, many natural pozzolans can be found. The results of the tests carried out on Taftan pozzolan indicate its proper activity so that at the range of 15 to $25 \%$ replacement with cement it shows the highest resistance [4].

It is possible to increase the density of particles in concrete by means of silica particles. The results of the tests carried out on silica nano particles indicate their good activity so that at the range of $1-4 \%$ replacement with cement they show the highest resistance [3]. The lightweight concrete has a high cost. However, considering the dead load of the structure, the size of foundations, column dimensions, the width of foundations beneath the walls and the decrease of thickness, the finished optimal roof is economically affordable. Here, micro and nano silica particles are used to fill the concrete pores and cavities and to increase its resistance [1]. In general, nano particles lead to the; increase of compressive strength and flexural strength of concrete, decrease of permeability, improvement of concrete infrastructure and cement paste, decrease of heat due to the hydration of cement in concrete, and the improvement of the pore size distribution in the infrastructure of cement paste and concrete [4].

\section{Concrete}

Concrete has been used as one of the most important materials in construction industry for many years and every day it is used in greater and huger projects due to its resistance to fire, erosion, weathering, etc, [1]. Durability and strength of concrete structures has drawn much attention 
towards itself in concrete technology. Therefore, much effort has been made to improve the strength and durability of concrete by adding specific materials [4].

\subsection{Definition of Concrete and its Different Types}

Concrete is a popular mixture of cement, water, and aggregates. Concrete is the most common and the most widely used construction material. This synthetic material has dedicated the highest rate of annual production to itself among the building materials. Cementitious materials are the most used construction materials. Therefore, concrete and cement mortars can be called the engine of construction industry around the world. This is not only due to the outstanding characteristics of concrete and cementitious materials compared to other similar materials bus also due to the low cost and low energy consumption and availability of raw materials [1]. Concrete can be divided into three categories in terms of its specific weight:

- Conventional concrete

- Lightweight concrete

- Heavyweight concrete

According to the definition, conventional concrete is the concrete which is made from normal Portland cement, type (I) and $(\mathrm{V})$. The specific weight of concrete is equal to 2200 to $2500 \mathrm{~kg} / \mathrm{m}^{3}$ (usually $2400 \mathrm{~kg} / \mathrm{m}^{3}$ ). The difference in specific weight ranging from 2200 to $2500 \mathrm{~kg} / \mathrm{m}^{3}$ results from the kind of aggregates and the concrete density. According to the American Concrete Institute (ACI), light weight concrete is defined as the concrete whose specific weight is significantly less than the specific weight of conventional concrete and is made of natural or crushed aggregates. Lightweight concrete is often used as a proper alternative and complement to the normal concrete in order to reduce the weight of structure although its ultimate compressive strength is less than normal concrete [2]. The most important advantage of the lightweight concrete compared to the normal concrete is its being light. Dead load of the building which is related to the weight of the structure is the principal force applied to bearing components of the structure and thus, its reduction leads to the reduction of incoming forces and the decrease of the weight of metal structure and walls which will be followed by the lower costs of the foundations. On the other hand, the lower weight of the structure reduces the transmitted force to the structure via the earthquake and also reduces its probable damage. The light weight of concrete components will be followed by the ease of transport and installation of prefabricated components, as well [1].

\subsection{Concrete Classification Based on the Strength [1, 2]}

Lightweight concretes are divided into categories in terms of strength including nonstructural lightweight concrete, and lightweight concrete with medium strength. Non-structural lightweight concrete which is usually used as the lightweight separator has the density of less than $800 \mathrm{~kg} / \mathrm{m}^{3}$. Despite the low density, its compressive strength is about 0.35 to $7 \mathrm{~N} / \mathrm{mm}^{2}$. The most common aggregates used in this type of concrete are perlite (a type of igneous rock) and vermiculite (a substance with a sheet structure like Lika). Structural lightweight concrete has sufficient strength and density, so that they can be used in structural components. The density of these kinds of concrete is usually between 1400 to $1900 \mathrm{~kg} / \mathrm{m}^{3}$ and the minimum compressive strength defined for them is $17 \mathrm{~N} / \mathrm{mm}^{2}$ (MPa). Sometimes it is possible to increase the strength up to $60 \mathrm{~N} / \mathrm{mm}^{2}$. In earthquake prone areas, the regulations limit the minimum compressive strength of lightweight concrete to 20 $\mathrm{N} / \mathrm{mm}^{2}$. Lightweight concrete with medium strength is placed between non-structural and structural lightweight concrete in terms of density and compressive strength, so that its compressive strength is ranged from 7 to $17 \mathrm{~N} / \mathrm{mm}^{2}$ and its density is ranged from 800 to $1400 \mathrm{~kg} / \mathrm{m}^{3}$.

\section{Architectural Features of Structure}

Building construction and architecture are two different concepts. The most important aspects of the structure are those that help the architecture form. The most important aspect of architecture is its positive effect on human behavior not to overcome them but to reinforce and strengthen the freedom. When the structure is mixed with the space, the architecture and the structure join together. The mixture of architecture and engineering is the ideal that must be achieved [6].

The application of simple and regulatory forms contributes to the stability and durability of the building and also increases the safety of tall buildings. Appropriate form of high-rise buildings and the sue of reasonable geometry can have many advantages in the proper behavior of the building against vertical forces and the improvement of building strength and stability against lateral forces such as wind or earthquake [6].

Form in its absolute sense means the combination, structure, or shape of everything [6]. Form can be defined as organized complexity. The key factors determining the form are geometry, performance, beauty, durability, and safety issues. Building forms can be divided into two general categories: regular and irregular. Regular forms are the ones that are subject to certain geometric rules. Platonic volumes such as those in Figure (2) are the most important regular forms [2]. Irregular forms do not have a regular geometric structure and their components are dissimilar in quality. Regular forms are more appropriate for high-rise buildings. The regular forms used in high-rise building can be divided into two categories in terms of the way of communication between spaces and the functions: centralized and strip forms. Centralized forms have central communication path while the strip forms of long communication paths not only provide the basic communication but also have horizontal paths [6].

Geometry is a form that can be used to achieve designing goals in creating a harmonious, appropriate, and sustainable form. Geometry is used as a logical base and an appropriate device for wisdom and creativity to design appropriate form for high-ride buildings. Designing is conveying the content in the framework of an architectural form. Appropriate form in a high-rise building with a reasonable geometry can create a lot of advantages in other aspects such as proper behavior of 
the structure against vertical forces and enhancing the strength and stability of the building against lateral forces like wind and earthquake [6].

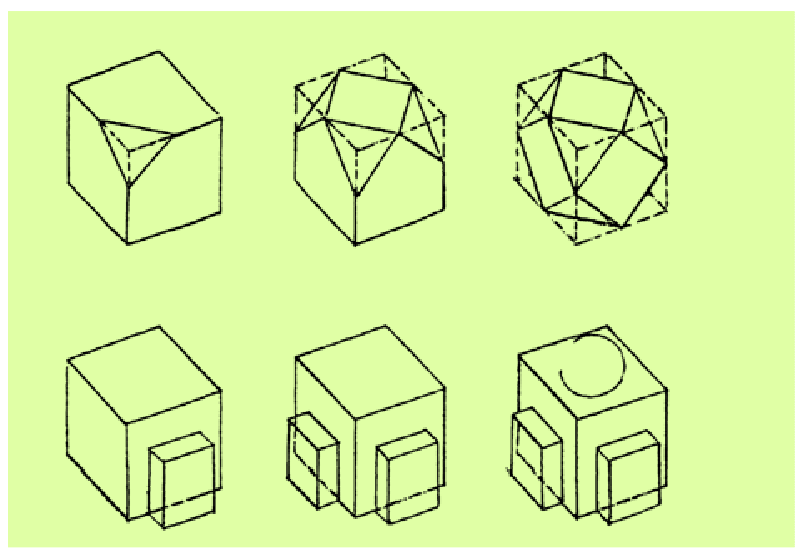

Figure 2. Simple changes in form [6]

According the Francois Sasha's theory, one of the most important issues in relation to the form of high-rise buildings is the significant impact of height in the formation of proportions of such buildings. Form analysts believe that accepting and understanding the forms that spread horizontally is much easier than vertical forms. Since great height inherent in high-rise buildings cannot seem favorable in human scale, it looks to be true at first.

\section{Sustainable Architecture}

The concept of sustainable development is the result of growing awareness of global bonds between growing environmental problems, social and economic issues, poverty, and inequalities on a healthy future for the mankind. Sustainable development highly binds environmental, social, and economic issues together. One of the environmental areas that sustainable development focuses on is the environmental issues. The task of architectures in this area is very sensitive because they are directly or indirectly responsible for $75 \%$ of climate changes. The sun is the source of various kinds of energy that exist in nature and solar energy is indestructible. The sun is one of the two major sources of energy that should be used because it doesn't require advanced and costly technologies and can be applied as a source of energy supply in most parts of the world. Solar architecture is a shortcut to achieve sustainable architecture [5].

\subsection{Characteristics of Sustainable Architecture}

The objectives of sustainable development in relation to the environment can be generally discussed in three areas which are close to each other semantically namely preserving the nature to meet the needs of future generations:

A. changing the relationship between human and nature: instead of rapid exploitation, the nature should be preserved.

B: Charting a course that focuses on a set of methods and ethics: controlling human behavior.
C: Changing mining: increasing the mines durability [5].

Sustainable development in relation to the construction activities and the build environment is often called sustainable building or structure. Sustainable development plans to crate major changes in understanding the relationship between man and nature. According to Richard Rogers sustainable design plans to meet future needs without destroying the natural resourcing remaining for the future generations. In relation to the buildings, sustainable design points to the efficiency of minimum energy resources, flexibility, and long life. Chart (1) displays the objectives of sustainable development.

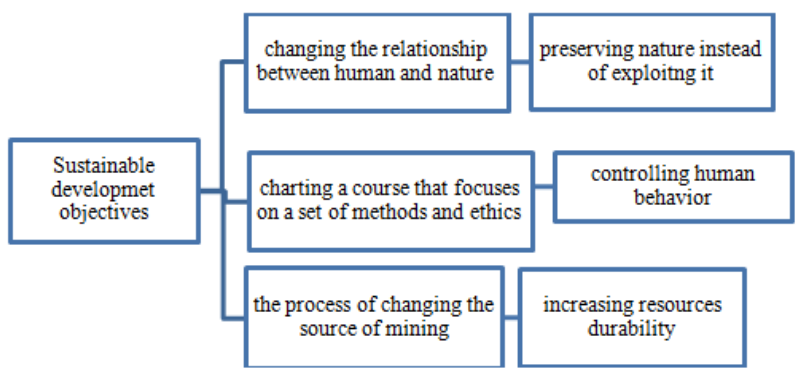

Chart 1. The objectives of sustainable development in relation to natural issues

The objectives of sustainable development in relation to environmental issues can be stated as the following: constructing buildings with minimum use of energy, flexibility, and long life; constructing buildings by using environmental technologies and considering cultural, social, and local contents. In order to achieve these objectives, the following points should be taken into consideration: paying attention to the consumption of energy and climatic design and considering the cultural, social, and local content for application of peripheral technologies [5]. Although the principles of sustainable agriculture include a wide range of application of the simplest methods to the most sophisticated technologies, the problem is the suitability of the method and its compatibility with social and cultural contents of the people and the users in that environment. Sustainable architecture needs to be seen in relation to the process as a power that sustains whatever that is capable of being sustainable.

\section{High-Rise Buildings}

In the twentieth century some issues such as population growth, the need for more accommodation of people in cities, the importance of using land in populated centers of the cities, the need for reconstructing and restoring urban areas, the people's demand to live and work in urban areas, and the requirement to reduce the costs resulting from horizontal expansion of cities have reflected the construction of high-rise buildings as a necessity in the world's major cities [6]. According to the mentioned points the objectives of sustainable architecture can be displayed as chart (2). 


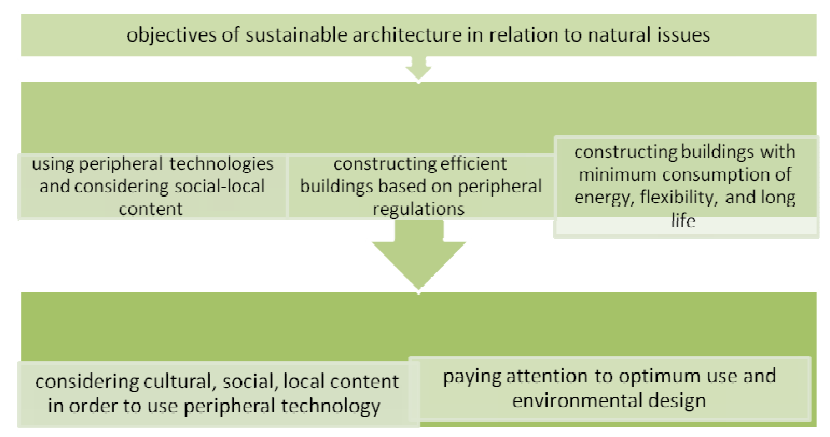

Chart 2. The objectives of sustainable architecture [5]

\subsection{Factors Influencing the Design of High-Rise Buildings [6]}

The main factors include: 1 . Particular circumstances of time and place; 2. Proportions and form; 3. Usage and performance; 4. In terms of the usage, in addition to single-use performance, some high-rise buildings are also used with the fusion of performances; 5 . Height and human scale: in order to create human scale in high-rise buildings, it is possible to create a depth of view towards the building and develop a good relationship with form in the audience. For creating a suitable human scale the surrounding space should not be so wide or extensive to make visual contact with it weak or impossible and of course it should not be so small to make humans afraid of the huge dimensions of the building in a an enclosed place. In figure (3) some examples of the form of high-rise buildings are illustrated.

\subsection{The Structure of a High-Rise Building in Terms of Environmental and Population Psychology}

Although the design of a high-rise building is the final result of a complicated process the element of which have interactive effect on each other and many factors such as cultural, social, and economic features influence it, it is possible to make appropriate and favorable use of high-rise buildings by observing the principles and criteria resulting from fundamental and practical research on architectural design, structure, and urban development. On the whole, given the particular circumstances of the current century, the appropriate and of course conditional use of high-rise buildings can be a realistic and appropriate solution to the accommodation of people and meeting the other needs related to social and economic activities in metropolises. Cognition of the psychological issues of the form is an essential factor to comprehend the form. Psychology of sensory perception and visual expression in relation to high-rise buildings is very important and plays an important role in the influence of form on the viewer [2].

\section{Results and Discussion}

Man is about to achieve unique abilities to change the surrounding environment. Nanotechnology has such an advantage that it doesn't cause problems in other features of the concrete by reforming the weaknesses of the concrete. Nanotechnology has created many advantages in concrete such as increasing the compressive and flexural strength of concrete, decreasing permeability, increasing the density of particles, etc. Each one of them has made an evolution in concrete industry.

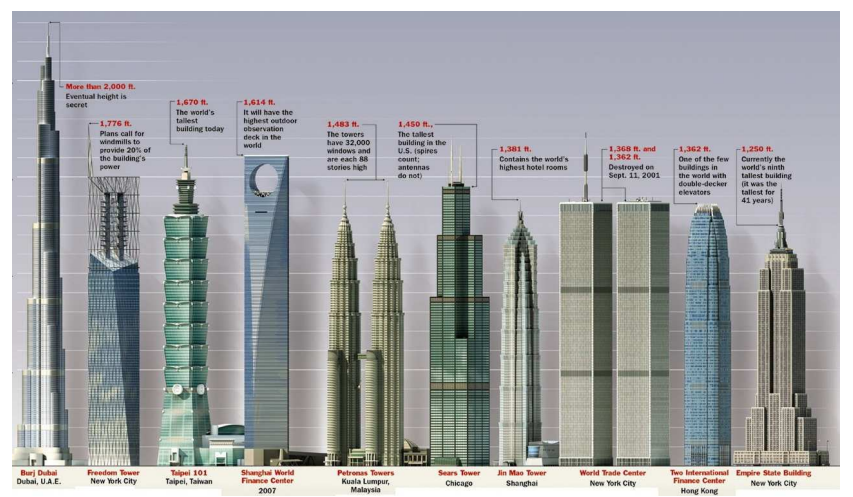

Figure 3. Examples of the form of high-rise buildings

Following the developments that nanotechnology has created in concrete industry, some changes have been made in buildings which have improved the situation or have somewhat changed the type of buildings. With regard to the people's need to the construction of high-rise buildings some measures have been considered for implementing such buildings that have often caused some problems in their construction. Nanoconcrete can solve the problem of constructing high-rise buildings due to its features. Here, the problem means the restrictions associated with the height of the buildings.

Proportions and forms of high-rise buildings are among the most important criteria for their construction. Stability and safety are the factors affecting the form of the buildings. To keep sustainability, a harmonious, appropriate, and stable form is required because form should be aligned to and consistent with sustainability. By increasing the compressive and flexural strength of concrete, nano makes the building form more flexible. Nanoconcrete can be used in order to achieve various forms so that the building strength is not faced with problem and it keeps its stability.

\section{Discussion and Conclusion}

Nowadays, after water, concrete is the most widely used material in the world. Using the unique characteristics of nano concrete such as functioning at room temperature, low creeping, capability of being formed in complex frames, capability of being used with other nano particles such as silica nano particles, it is possible to use it effectively for making new materials with extraordinary capabilities. Nanotechnology has such an advantage that it doesn't cause problems in other features of the concrete by reforming the weaknesses of the concrete. Nanotechnology has proved that it is able to wholly improve the concrete performance. Some advantages are: 
- Due to high activity of nano-silica pozzolan and its increasing strength, it can be used in concretes containing Taftan pozzolan to compensate for the loss of resistance resulting from Taftan pozzolan.

- The use of nano particles causes the increase of compressive strength, decrease of permeability, improvement of concrete infrastructure and cement paste, decrease of heat due to the hydration of cement in concrete, and the improvement of the pore size distribution in the infrastructure of cement paste and concrete.

- the design of a high-rise building is the final result of a complicated process the element of which have interactive effect on each other and many factors such as cultural, social, and economic features influence it. However, it is possible to make appropriate and favorable use of high-rise buildings by observing the principles and criteria resulting from fundamental and practical research on design, and architecture of structure.

- The use of simple and regular forms improves the stability and durability of the building and increases the safety.

- By increasing the compressive and flexural strength of concrete, nano makes the building form more flexible. Nanoconcrete can be used in order to achieve various forms.

- The concept of sustainable development is an important interpretation on understanding the relationship between human and nature and also human beings with one another. Many theorists are seeking to look at nature in such a way that leads to respectful behavior towards the nature. Given the extent of sustainability and its complicated components it is necessary to note that sustainability is considered as the product of architecture process.

- Solar energy is an indestructible kind of energy and its application in building results in economic savings, durability, comfort, and easy maintenance.

- By moving towards the use of nanotechnology in all stages of the construction of a high-rise building and also improving the structural features of the building and considering nano in all materials it is possible to construct better and more beautiful buildings.

\section{Acknowledgement}

The authors highly express their thanks to the vice chancellor for research and education at Toos Higher Education Institute and dedicate this article to the student researchers.

\section{References}

[1] Ahmadi Moghadam, H., Kamran Zadeh Foomani, M., Tafaroj Fakoor, N. "Lightweight nanoconcrete", Journal of Technology and Arts, Construction Engineering Organization, Gilan Province, 52, Civil: 8 -13, 2011.

[2] Bagheri, F., Keyvanloo, S. "Suggesting innovative panel with acrylic concrete to beautify the buildings". The $2^{\text {nd }}$ Conference on Interior Architecture and Decoration, Danesh Pajoohan Institute of Higher Education, Isfahan, 2012.

[3] Khazaeni, G., Khanzadi, M., Tadayon, M. The effect of silica nano particles on the improvement of mechanical properties of concrete by increasing the grade of cement", Journal of Transportation, 8 (10): 11- 20, Spring. 2011.

[4] Shekarchi Zadeh, M., Valipour, M., Pargar, F. "The effect of micro silica pozzolan, metakaolin, zeolite, and polypropylene fibers on the resistance to chloride penetration into concrete in environmental conditions of Qeshm Island", Journal of Civil Engineering, 22 (1): 83 - 96, 2010.

[5] Kamel Nia, H., Taghaboni, A. "Conceptualization in architecture (a comparison of the features of the contemporary concept-oriented architecture and concept-oriented art)", Journal of the University of Arts, 8 (2): 93 - 110, Letter of Architecture and Urban Development, Spring and Summer, 2009.

[6] Golabchi, M. "Criteria for the design and construction of high-rise buildings", Bulletin of Fine Arts, 9: 52 - 62, 2008. 